\title{
O Indicador de Desenvolvimento Regional no Território do Tocantins
}

\author{
The Regional Development Indicator in the Tocantins Region \\ Indicateur de Développement Régional du Territoire de Tocantins \\ Indicador del Desarrollo Regional em el Territorio del Estado de Tocantins
}

\author{
Nilton Marques Oliveira ${ }^{1}$ \\ Moacir Piffer ${ }^{2}$ \\ Udo Strassburg ${ }^{3}$
}

Recebido em 17/05/2017; revisado e aprovado em 16/08/2017; aceito em 29/08/2017

DOI: http://dx.doi.org/10.20435/inter.v0i0.1607

\begin{abstract}
Resumo: O presente artigo tem por objetivo analisar o desenvolvimento regional do Estado do Tocantins, a partir da elaboração do Indicador de Desenvolvimento Regional (IDR) entre 2000 e 2010, com dados secundários coletados. Os principais resultados sugerem que no IDR do território do Estado do Tocantins, que possuía 139 municípios em 2000, apenas 15 foram classificados como polos de desenvolvimento, 34 em estágio intermediário e 90 em estágio retardatário. Conclui-se que houve melhoria no IDR em todo território do Tocantins, no entanto, nos municípios localizados ao longo da BR-153 (Belém-Brasília), as atividades econômicas mostraram-se mais dinâmicas.
\end{abstract}

Palavras-chave: Indicador de desenvolvimento regional (IDR); território do Tocantins; desigualdades sociais e econômicas.

Abstract: This paper aims to analyze the regional development of the State of Tocantins, on the basis of the elaboration of the Regional Development Indicator (RDI) from 2000 to 2010, with secondary data. The main results suggest that the RDI of the region of the Tocantins State, which had 139 municipalities in 2000, only 15 were classified as development poles, 34 in the intermediate stage, and 90 in the late stage. It was concluded that there was an improvement in RDI in all regions of Tocantins State; however, in the municipalities along the BR-153 (Belém-Brasilia High Way), economic activities were more dynamic.

Keywords: Regional development indicator (IDR); regions of Tocantins; social and economic inequalities.

Résumé: Cet article vise analyser le développement régional de Tocantins à partir de l'élaboration de l'Indice de Développement Régional (IDR) entre 2000 et 2010, des données secondaires recueillies. Les principaux résultats de I'IDR du territoire de Tocantins montrent que des 139 municipalités en 2000, seules 15 ont été classées comme pôle de développement, 34 ont été classées à une étape intermédiaire et 90 dans phase retardataire. L'article conclut qu'il y a eu amélioration dans l'IDR à travers le territoire de Tocantins. Cependant, les activités économiques dans les municipalités situées auprès de BR-153 (Belém-Brasília) ont été plus dynamiques.

Mots-clés: Indicateur de developpement régional; Territoire de Tocantins; Inégalités sociales et économiques.

Resumen: El presente artículo, tiene como objetivo analizar el desarrollo regional de Tocantins, a partir de la elaboración del Indicador de Desarrollo Regional (IDR) entre 2000 y 2010, com datos secundarios recolectados. Los principales resultados sugieren que en IDR del territorio de Tocantins, de los 139 municipios em 2000, apenas 15 fueran catalogados como polo de desarrollo, 34 como en estado intermédio y 90 en estado atrasado. Concluyo que hubo una mejoría en el IDR en todo el territorio de Tocantins, pero en los municipios localizados a lo largo de la BR-153 (Belém-Brasília) las actividades económicas se muestran más dinámicas. Palabras claves: indicador de desarrollo regional; territorio de Tocantins; desigualdades sociales y económicas.

\footnotetext{
${ }^{1}$ Universidade Federal do Tocantins (UFT), Palmas, Tocantins, Brasil.

${ }^{2}$ Universidade Estadual do Oeste do Paraná (UNIOESTE), Toledo, Paraná, Brasil.

${ }^{3}$ Universidade Estadual do Oeste do Paraná (UNIOESTE), Cascavel, Paraná, Brasil.
} 


\section{INTRODUÇÃO}

Desenvolvimento regional compreende uma análise de fatores sociais e econômicos no interior de uma região, fatores esses que compõem a mobilidade espacial do capital, do trabalho e das inovações. Tais fatores, quando bem ou mal empregados em uma determinada região, podem reduzir ou acelerar as desigualdades regionais.

Identificar aspectos do desenvolvimento regional poderá auxiliar na implantação de políticas públicas de atendimento à população, auxiliando no processo de desenvolvimento. Nesse sentido, a atenção volta-se para implementar um desenvolvimento voltado para as especificidades de cada território, de forma a integrar os fatores sociais, culturais, econômicos e políticos.

O desenvolvimento regional constitui um processo de transformação social, econômico, cultural e político. Essas transformações são questões centrais para se entender a evolução da dinâmica dos setores produtivos de uma região. As teorias de desenvolvimento regional estão próximas à posição da corrente institucionalista. Esta, advoga que as instituições são o resultado de um processo seletivo e adaptativo que modela os tipos prevalecentes, ou dominantes, de atitudes ou aptidões (NORTH, 1994).

Assim, este artigo tem por objetivo analisar o desenvolvimento regional do Tocantins, a partir da elaboração do Indicador de Desenvolvimento Regional (IDR) contemplando variáveis sociais e econômicas. Para tanto, a construção do IDR considerou a análise específica dos indicadores parciais inerentes aos cálculos das 17 variáveis sociais e econômicas, comparadas entre 2000 e 2010 para os 139 municípios do Estado do Tocantins. Dessa forma, torna-se fundamental conhecer os aspectos que compõem cada espaço, bem como a dinâmica interna dos municípios tocantinenses.

Isto posto, este artigo está dividido em cinco partes, sendo a primeira a introdução, a seguir se apresenta uma breve revisão sobre o território e desenvolvimento regional. A terceira referese aos aspectos metodológico. Na quarta, discutem-se os principais resultados da pesquisa e, por fim, as considerações finais sumarizam o artigo.

\section{TERRITÓRIO E DESENVOLVIMENTO REGIONAL}

Tendo como enfoque o desenvolvimento regional, esta pesquisa aborda brevemente o conceito de território. Segundo Haesbaert (2009), o território surge como o espaço concreto, com seus atributos naturais, socialmente construídos, apropriado e ocupado por um grupo social. Para Haesbaert (1997), Bourdieu (1989) e Sposito (2000), os conceitos de território vinculam-se aos sentimentos e aos simbolismos atribuídos aos lugares.

O território é um espaço definido e delimitado por e pela relação de poder, indo além da abordagem política, haja vista que congrega aspectos culturais dos múltiplos territórios, os quais incluem atores sociais, políticos e econômicos. O enfoque que Sposito (2000) dá ao conceito de território diz respeito à territorialidade e apreensão, mesmo que a abordagem carregue forte conotação cultural. A territorialidade, nesse caso, pertence ao mundo dos sentidos e, portanto, da cultura, das interações, cuja referência básica é a pessoa e sua capacidade de se localizar e se deslocar.

Nas palavras de Zaoual (2006), cada território é uma entidade imaterial que impregna o conjunto da vida em dado meio, com suas crenças, mitos, valores e experiências passadas, conscientes ou inconscientes, ritualizadas. Ao lado desse aspecto feito de mitos e ritos, o território 
possui seus conhecimentos empíricos e/ou teóricos, de fato um saber social acumulado durante sua trajetória.

A ocupação do território é geradora de raízes e de identidade. Um grupo não pode mais ser compreendido sem seu território, sem sua identidade social e cultural das pessoas. O território não deixa de ser importante, não apenas por ser espaço próprio do Estado, mas também de diferentes atores sociais, que manifestam seu poder sobre uma área específica, onde, na presente pesquisa, no Estado do Tocantins, essa manifestação de poder está ligada ao ambiente histórico e institucional (RAFFESTIN, 1993).

O território visto nessa perspectiva é um espaço onde se projetou um trabalho, seja de energia ou de informação e que, por consequência, revela reações marcadas pelo poder. Nesse ponto, enfatiza-se uma categoria essencial para a compreensão do território que é o poder exercido por pessoas ou grupos. Poder e território, embora conceitos construídos, cada um, com sua autonomia, doravante serão enfocados conjuntamente para a consolidação do conceito de território (SPOSITO, 2000; SAQUET, 2003).

Nessa corrente, o desenvolvimento regional complementa o fazer do território, constituído em um processo de transformação social, econômico, cultural e político. Essas transformações são questões centrais para se entender a evolução da dinâmica dos setores produtivos de uma região. O desenvolvimento regional, na acepção de Lopes (2001), será o fio condutor de orientação da necessidade de elaborar políticas e formular planos que as programem em suas devidas proporções, levando em consideração as características que as regiões apresentam, sejam elas subdesenvolvidas, deprimidas ou congestionadas.

Bresser-Pereira (2008) argumenta que o desenvolvimento econômico de uma região é um processo de acúmulo de capital que, aliado ao progresso técnico, possibilita aumento de produtividade, dos salários e do padrão médio de vida da população.

North $(1991 ; 1994)$ posiciona que, quando se trata de abordar sobre desenvolvimento econômico, deve-se levar em conta o conhecimento econômico histórico e teórico. Sua análise recai sobre o conceito histórico, dando ênfase ao ambiente institucional e ao conceito do path dependence ${ }^{4}$, explicando os resultados econômicos alcançados em função de decisões passadas, e não relacionadas às condições presentes.

As instituições fazem parte como o principal regulador das atividades e interações humanas. North $(1991 ; 1994)$ expõe em sua obra um marco analítico para explicar como as instituições e as mudanças institucionais afetam o desenvolvimento social e econômico. As instituições existem devido à incerteza que resulta da interação humana. North parte da premissa de que o mercado acarreta custos na economia, ideia de Coase (1937), e que a diminuição de tais custos decorre da existência de instituições.

Autores como Boisier (2000), Lopes (2001) e Furtado (2009) advogam que o desenvolvimento regional é impulsionado por uma política de Estado junto com a sociedade civil organizada, tendo o planejamento como elemento chave nas proposituras das políticas regionais de desenvolvimento, levando em conta sua especialidade geográfica, a pressão populacional sobre os recursos naturais, sua organização social, estruturas religiosas, mentais e culturais. Além disso, leva-se em conta seu processo histórico de produção e de consumo.

\footnotetext{
${ }^{4}$ A ideia central do path dependence expressa o caráter irreversível e histórico do sistema capitalista, significa uma ligação do passado com o presente e o futuro, que, segundo North (1994), as instituições apresentam característica históricas determinadas.
} 
O desenvolvimento regional deve ser visto de forma multidimensional, pois perpassa por diversos fatores sociais, econômicos, estruturais, educacionais, ambientais, que podem determinar ou não o desenvolvimento de uma determinada região. É provável que alguns desses fatores tenham contribuído para a formação do Estado do Tocantins.

\section{ASPECTOS METODOLÓGIGOS}

A partir do levantamento bibliográfico acerca dos indicadores sociais e econômicos, este artigo utilizou como base metodológica os estudos regionais, compostos pelo Indicador de Desenvolvimento Regional (IDR) proposto por Gualda (1995; 2003), Oliveira (2005); Ferrera de Lima et al. (2012) e Rodrigues e Ferrera de Lima (2013), os quais foram adaptados para elaborar o IDR para os municípios do Tocantins.

Com relação ao levantamento dos dados, esta pesquisa se caracterizou como exploratória e descritiva, pois buscou a compreensão de fenômenos sociais e econômicos a partir da localização, avaliação e síntese dos dados e informações em determinado período de tempo e espaço.

Os dados foram coletados no Instituto Brasileiro de Geografia e Estatística (IBGE), na base de dados do Instituto de Pesquisa Econômica Aplicada (IPEADATA), Secretaria de Fazenda do Estado do Tocantins (SEFAZ), Programa das Nações Unidas para o Desenvolvimento (PNUD) e Relação Anual de Informações Sociais (RAIS) do Ministério do Trabalho e Emprego. O elemento de estudo concentrou-se nos 139 municípios do Estado do Tocantins, correspondente aos anos de 2000 e 2010. A escolha de dois períodos distintos permitiu avaliar o comportamento e suas respectivas modificações.

Com base na escolha das variáveis, estimou-se o IDR a partir dos indicadores parciais: social e econômico. O indicador parcial social $\left(I S_{i}\right)$ com seus respectivos pesos, foi apresentado na Equação (01), e indica, mediante uma série de variáveis, o perfil do desenvolvimento social de cada município.

$I S_{i}=(\operatorname{IPU} \times 0,05+$ IPR $\times 0,05+$ ICE $\times 0,15+$ IMAE $\times 0,15+$ IMH x $0,10+$ IAE $\times$ $0,10+$ ICL $\times 0,05+$ ILH x $0,05+$ IDSS x $0,10+$ IPP x $(-0,10)+$ IDEC x 0,10) x P

Em que: ISi é o Indicador parcial; IPU = Índice de participação da população urbana do município i; IPR = Índice de participação da população rural do município i; ICE = Índice de consumo de energia residencial do município i; IMAE = Índice de média de anos de estudo do município i; IMH = Índice de médicos por mil habitantes do município i; IAE= Índice das unidades abastecidas com água encanada do município i; ICL = Índice de coleta de lixo do município i; ILH = Índice de leitos hospitalares por habitantes do município i; IDSS = Índice de despesas com saneamento e saúde do município i; IPP = Índice de pessoas pobres do município i; IDEC = Índice de despesas com educação e cultura do município i; P é a participação da variável Wi do município i.

O indicador parcial econômico (IEi) comporta variáveis que descrevem a situação econômica dos municípios do Estado do Tocantins, permitindo apontar as condições que eles possuem para gerar investimentos em: infraestrutura, saúde, educação, pesquisa e desenvolvimento e geração de emprego, conforme apresentado na Equação (02), com seus respectivos pesos.

$I E i=($ IPIB $\times 0,30+$ ICMS x 0,15 + IFPM x 0,05+ICES x $0,05+$ IPVA x 0,05 + IE x 0,40) 
Em que: IEi é o Indicador parcial econômico; IPIB = Índice da Participação do Produto Interno Bruto do município i; ICMS i; IFPM = Índice do Fundo de participação do município i; ICES = Índice do Consumo de energia elétrica setorial do município i; IPVA: Índice de participação do IPVA arrecadado do município i; $\mathrm{IE}_{\mathrm{i}}=$ Índice da participação do emprego total do município i.

O índice de participação da variável Wi do município "i” (P) e o índice da variável Wi do município "i" (IPWi) foram estimados por meio das Equações (03) e (04).

Part. $=\frac{W_{i}}{\sum W_{i}}$

Em que: Wi é o valor da variável no município, e, $\Sigma$ Wi corresponde ao valor total do Estado.

$I P W i=\frac{W_{i}-W_{\min }}{W_{\max }-W_{\min }}$

Em que: IPWi é o índice da variável $W$ do município $i$; Wi a participação da variável $W$ do município i; Wmin fator que corresponde à participação do município com o menor valor; e, Wmax é a participação do município com o maior valor.

Após as estimativas, o IDR é calculado conforme os resultados das Equações (01) e (02) estabelecendo os seus respectivos pesos de acordo com a Equação (05). Foi dado maior peso para o indicador econômico $(0,6)$, pois o município com melhor situação econômica possui melhores condições para investir em infraestrutura básica, sem contar com a capacidade de gerar empregos e assim, melhorar seu indicador social $(0,4)$.

$I D R_{i}=\left(I S_{i} \times 0,4\right)+\left(I E_{i} \times 0,6\right)$

Considerando os resultados da Equação (05), o IDR é classificado em três categorias que representam o estágio de desenvolvimento dos municípios. No Quadro 01, é apresentado a classificação do IDR.

Quadro 1 - Classificação do Índice de Desenvolvimento Regional (IDR)

\begin{tabular}{|c|c|}
\hline Municípios Polos & IDR de 1,0 a 0,1 \\
\hline Municípios Intermediários & IDR de 0,099 a 0,050 \\
\hline Municípios Retardatários & IDR abaixo de 0,050 \\
\hline
\end{tabular}

Fonte: Gualda (1995; 2003), Ferrera de Lima et al. (2012), Rodrigues e Ferrera de Lima (2013) adaptado pelos autores.

Os municípios que apresentaram IDR igual ou superior a 0,1 foram classificados como municípios polos de desenvolvimento regional. Apresentam uma dinâmica na sua base produtiva com potencial de crescimento e de consumo. Os municípios cujo IDR situa-se no intervalo compreendido entre 0,099 a 0,050 foram considerados como intermediários, ou seja, apresentaram uma estrutura econômica e social em crescimento, não obstante, sua dinâmica seja inferior à dos municípios polos, pois conseguem atrair recursos e renda dos municípios retardatários. Os municípios com IDR abaixo de 0,050 foram considerados retardatários, pois 
não apresentaram nenhuma capacidade de implementar um processo de crescimento e desenvolvimento econômico, pois não conseguem reter ou atrair recursos de forma a assegurar as condições mínimas de um processo de desenvolvimento regional (GUALDA, 1995; 2003; FERRERA DE LIMA et al., 2012; RODRIGUES; FERRERA DE LIMA, 2013).

A Figura 1 e o Quadro 1 representam a localização dos 139 municípios do Estado do Tocantins, com sua respectiva numeração. De acordo com o Censo Demográfico do IBGE (2010), o Estado do Tocantins possui uma população de 1.383,3 mil habitantes, o que representa 0,73\% de população do país e $8,82 \%$ da população da região Norte. A densidade demográfica é de 4,98 hab $/ \mathrm{km}^{2}$, e a composição demográfica é composta de $79 \%$ de população urbana e 31\% de população rural.

O crescimento econômico e a urbanização do Estado do Tocantins, de fato, só vieram a acontecer a partir da primeira década do século XXI. A sua população teve um crescimento médio de 22,5\%, no período de 2000 a 2010 e, em relação ao Produto Interno Bruto, foi o Estado que mais cresceu no acumulado entre 2002 e 2010, 74,2\% em termos absolutos (IBGE, 2012). Quanto à criação de emprego formal, em 2000, o Estado contava com 106.040 e, em 2013, esse número passou para 257.536, um crescimento de mais 142\% (MINISTÉRIO DO TRABALHO E EMPREGO [MTE], 2014).

O setor produtivo tem passado por um processo de expansão que poderá proporcionar que assuma uma posição mais relevante no cenário nacional nos próximos anos. Tanto o estado do Tocantins como a capital Palmas apresentam grande desigualdade social e econômica.

Analisando os dados citados sobre o Estado do Tocantins, estes apresentam crescimento econômico, porém, para que o desenvolvimento regional possa acontecer, envolve-se um conjunto mais amplo de variáveis, desde econômicas, sociais, ambientais, culturais e institucionais. Conhecendo os potenciais produtivos e sabendo das disparidades econômicas e sociais de todos os municípios, pode-se subsidiar políticas de desenvolvimento local com o objetivo de alavancar o potencial de cada localidade, principalmente dos municípios menos desenvolvidos, com o intuito de reduzir as desigualdades inter e intra municipais do Tocantins. 
Figura 1 - Representação da localização dos Municípios do Estado do Tocantins

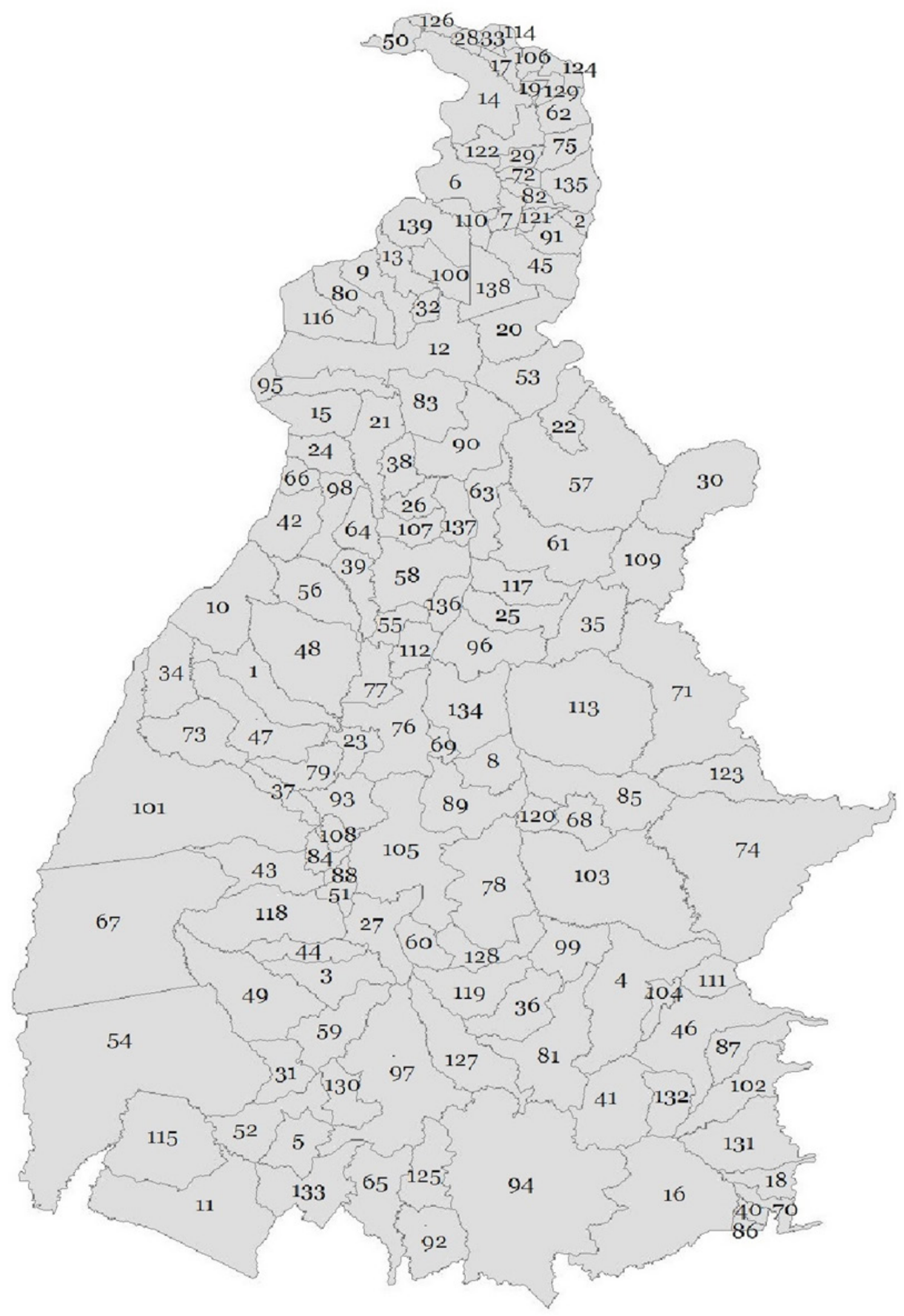

Fonte: IBGE (2010), adaptado pelos autores. 
Quadro 1 - Relação dos Municípios do Estado do Tocantins

\begin{tabular}{|c|c|c|c|c|c|}
\hline \multicolumn{6}{|c|}{ Municípios do Estado do Tocantins } \\
\hline 1 & Abreulândia & 48 & Dois Irmãos do Tocantins & 95 & Pau d'139/3Arco \\
\hline 2 & Aguiarnópolis & 49 & Dueré & 96 & Pedro Afonso \\
\hline 3 & Aliança do Tocantins & 50 & Esperantina & 97 & Peixe \\
\hline 4 & Almas & 51 & Fátima & 98 & Pequizeiro \\
\hline 5 & Alvorada & 52 & Figueirópolis & 99 & Pindorama do Tocantins \\
\hline 6 & Ananás & 53 & Filadélfia & 100 & Piraquê \\
\hline 7 & Angico & 54 & Formoso do Araguaia & 101 & Pium \\
\hline 8 & Aparecida do Rio Negro & 55 & Fortaleza do Tabocão & 102 & Ponte Alta do Bom Jesus \\
\hline 9 & Aragominas & 56 & Goianorte & 103 & Ponte Alta do Tocantins \\
\hline 10 & Araguacema & 57 & Goiatins & 104 & Porto Alegre do Tocantins \\
\hline 11 & Araguaçu & 58 & Guaraí & 105 & Porto Nacional \\
\hline 12 & Araguaína & 59 & Gurupi & 106 & Praia Norte \\
\hline 13 & Araguanã & 60 & Ipueiras & 107 & Presidente Kennedy \\
\hline 14 & Araguatins & 61 & Itacajá & 108 & Pugmil \\
\hline 15 & Arapoema & 62 & Itaguatins & 109 & Recursolândia \\
\hline 16 & Arraias & 63 & Itapiratins & 110 & Riachinho \\
\hline 17 & Augustinópolis & 64 & Itaporã do Tocantins & 111 & Rio da Conceição \\
\hline 18 & Aurora do Tocantins & 65 & Jaú do Tocantins & 112 & Rio dos Bois \\
\hline 19 & Axixá do Tocantins & 66 & Juarina & 113 & Rio Sono \\
\hline 20 & Babaçulândia & 67 & Lagoa da Confusão & 114 & Sampaio \\
\hline 21 & Bandeirantes do Tocantins & 68 & Lagoa do Tocantins & 115 & Sandolândia \\
\hline 22 & Barra do Ouro & 69 & Lajeado & 116 & Santa Fé do Araguaia \\
\hline 23 & Barrolândia & 70 & Lavandeira & 117 & Santa Maria do Tocantins \\
\hline 24 & Bernardo Sayão & 71 & Lizarda & 118 & Santa Rita do Tocantins \\
\hline 25 & Bom Jesus do Tocantins & 72 & Luzinópolis & 119 & Santa Rosa do Tocantins \\
\hline 26 & Brasilândia do Tocantins & 73 & Marianópolis do Tocantins & 120 & Santa Tereza do Tocantins \\
\hline 27 & Brejinho de Nazaré & 74 & Mateiros & 121 & Santa Terezinha do Tocantins \\
\hline 28 & Buriti do Tocantins & 75 & Maurilândia do Tocantins & 122 & São Bento do Tocantins \\
\hline 29 & Cachoeirinha & 76 & Miracema do Tocantins & 123 & São Félix do Tocantins \\
\hline 30 & Campos Lindos & 77 & Miranorte & 124 & São Miguel do Tocantins \\
\hline 31 & Cariri do Tocantins & 78 & Monte do Carmo & 125 & São Salvador do Tocantins \\
\hline 32 & Carmolândia & 79 & Monte Santo do Tocantins & 126 & São Sebastião do Tocantins \\
\hline 33 & Carrasco Bonito & 80 & Muricilândia & 127 & São Valério da Natividade \\
\hline 34 & Caseara & 81 & Natividade & 128 & Silvanóplis \\
\hline 35 & Centenário & 82 & Nazaré & 129 & Sítio Novo do Tocantins \\
\hline 36 & Chapada da Natividade & 83 & Nova Olinda & 130 & Sucupira \\
\hline 37 & Chapada de Areia & 84 & Nova Rosanlândia & 131 & Taguatinga \\
\hline 38 & Colinas do Tocantins & 85 & Novo Acordo & 132 & Taipas do Tocantins \\
\hline 39 & Colméia & 86 & Novo Alegre & 133 & Talismã \\
\hline 40 & Combinado & 87 & Novo Jardim & 134 & Tocantínia \\
\hline 41 & Conceição do Tocantins & 88 & Oliveira de Fátima & 135 & Tocantinópolis \\
\hline 42 & Couto de Magalhães & 89 & Palmas & 136 & Tupirama \\
\hline 43 & Cristalândia & 90 & Palmeirante & 137 & Tupirantins \\
\hline 44 & Crixás do Tocantins & 91 & Palmeiras do Tocantins & 138 & Wanderlândia \\
\hline 45 & Darcinópolis & 92 & Palmeirópolis & 139 & Xambioá \\
\hline 46 & Dianópolis & 93 & Paraíso do Tocantins & - & - \\
\hline 47 & Divinópolis do Tocantins & 94 & Paranã & - & - \\
\hline
\end{tabular}

Fonte: Figura 1 (IBGE, 2010). 


\section{INDICADOR SOCIAL PARCIAL DO ESTADO DO TOCANTINS}

A análise dos resultados do indicador social dos 139 municípios do Estado do Tocantins demonstrou que, em 2000, havia seis municípios classificados como polos, a saber: Palmas, a capital, com o melhor indicador social $(0,290)$, seguido de Araguaína $(0,205)$, Gurupi $(0,174)$, Paraíso do Tocantins $(0,152)$, Porto Nacional $(0,124)$ e Miracema $(0,11)$. Do total de municípios, 4,3\% foram classificados como polos de desenvolvimento, 23,7\% em estágios intermediários e 72\% como municípios retardatários.

Dos 33 municípios intermediários, os melhores índices foram obtidos em: Guaraí $(0,099)$, Colinas do Tocantins $(0,098)$, Pedro Afonso $(0,089)$, Formoso do Araguaia $(0,088)$, Alvorada $(0,086)$, Cristalândia $(0,084)$.

Foram classificados 100 municípios retardatários e, dentre estes, 19 foram classificados como os piores, em 2000, os quais foram: Esperantina $(-0,023)$, Mateiros $(-0,022)$, Juarina $(-0,001)$, Carrasco Bonito $(-0,018)$, Barra do Ouro $(-0,016)$, Praia Norte $(-0,015)$, Palmeirante $(-0,015)$, Lagoa do Tocantins $(-0,014)$, Riachinho $(-0,011)$, Campos Lindos $(-0,010)$, Maurilândia $(-0,008)$, Santa Terezinha do Tocantins $(-0,007)$, Santa Maria do Tocantins $(-0,006)$, São Salvador do Tocantins $(-0,004)$, Cachoeirinha $(-0,004)$, Sampaio $(-0,004)$, Itapiratins $(-0,003)$, Muricilândia $(-0,003)$ e São Bento do Tocantins $(-0,002)$.

Dentre os 19 piores municípios em 2000, nove estão localizados na Microrregião do Bico do Papagaio, cinco no Jalapão e cinco em Dianópolis. Essas microrregiões possuem os piores indicadores de desenvolvimento, com elevados índices de pobreza, precariedade em infraestrutura, pouca atividade econômica, grande parte dos empregos provém do poder público municipal, e a grande maioria dessa população sobrevive com a transferência de renda do governo federal, via bolsa família, aposentadoria rural e benefício social.

A Figura 2 apresenta a distribuição do indicador social nos municípios, em 2000 e 2010, conforme a classificação adotada para eles. Percebeu-se uma concentração dos melhores indicadores sociais, nos municípios localizados à margem da rodovia Belém-Brasília. Há uma maior dispersão dos municípios retardatários e uma polarização dos municípios intermediários, próximos aos municípios polos de desenvolvimento.

Não obstante, em 2010, teve uma significativa melhora das variáveis que compõem o indicador social, os municípios polos passaram para 9 em 2010, com participação de 6,5\% do total, e os municípios intermediários, 78, correspondem a 56\% do total. Os melhores desempenhos ficaram com os municípios considerados retardatários, houve uma redução, passando de 100, para 52 municípios em 2010. A conquista desse desempenho se deve, sobretudo, à queda da taxa de pessoas pobres nesses municípios, via transferência de renda (Bolsa Família) aumento com gastos em educação, em cultura, em saneamento e em saúde, além do aumento da taxa de urbanização, melhora na média de anos de estudos, aumento no abastecimento de água encanada e na coleta de lixo.

A classificação dos municípios com o melhor indicador social não se alterou em 2010, conforme a Figura 2, Palmas, a capital do estado, apresentou o melhor indicador $(0,340)$ seguido de Araguaína (0,248), Gurupi $(0,155)$, Paraíso do Tocantins $(0,138)$, Porto Nacional $(0,131)$, Colinas $(0,113)$, Miracema $(0,112)$, Tocantinópolis $(0,107)$, Guaraí $(0,106)$. 
Figura 2 - Distribuição do Indicador Social no Território do Tocantins - 2000 e 2010

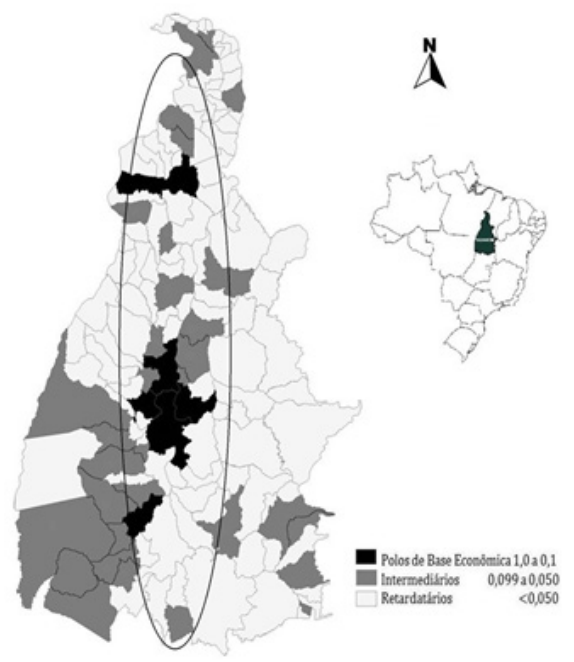

2000

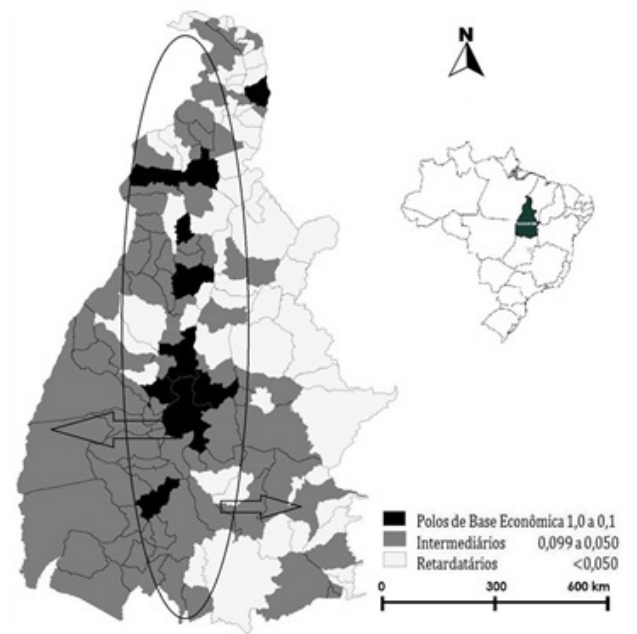

2010

Fonte: Adaptado do IBGE (2000; 2010).

Apenas dois municípios apresentaram indicador social negativo, os quais foram: Ponte Alta do Bom Jesus $(-0,002)$ e Lizarda $(-0,006)$.

Na Figura 2, constatou-se que a dinâmica de crescimento e desenvolvimento se dá ao longo do traçado da rodovia Belém-Brasília, no entanto não significa que, nesse traçado, tenha ocorrido desenvolvimento em todos os municípios. Pode se inferir que, tanto no aspecto social quanto econômico, a BR-153 se apresenta como um corredor de desenvolvimento. Para Perroux (1977), corredor é o espaço que une dois polos de base diversificada ou de manutenção.

Observou-se, também, que houve melhora na parte oeste do estado, no que tange à expansão da pecuária e nos plantios de soja e arroz irrigado nas Microrregiões Formoso do Araguaia, Gurupi, Miracema e Araguaína, aumentando, assim, os municípios intermediários, e reduzindo o número de municípios retardatários, na parte leste, nas Microrregiões do Jalapão, Dianópolis, Bico do Papagaio.

A melhora do indicador social começou a partir dos municípios intermediários, mas a grande diferença foi entre os municípios considerados retardatários. Infere-se, portanto, que as políticas implementadas no Tocantins, como o gasto em educação, saúde, saneamento básico, água tratada, transferência de renda, via programas do Governo Federal e estadual, vêm a cada ano melhorando a qualidade de vida dos moradores desses municípios tocantinenses.

\subsection{Indicador Econômico Parcial do Estado do Tocantins}

A análise dos resultados do indicador econômico dos 139 municípios do Estado do Tocantins permitiu identificar que, no ano de 2000 , 2\% do total de municípios foram classificados como polo, 3,5\% dos municípios em estágio intermediário e 95,5\% em estágio retardatário. Os três municípios classificados como polo no indicador econômico foram: Palmas, a capital do estado com 0,580; Araguaína com 0,303; e Gurupi com 0,246. Os municípios em estágio intermediário foram: Porto Nacional $(0,098)$, Paraíso do Tocantins $(0,089)$, Miracema do Tocantins $(0,076)$, Formoso do Araguaia $(0,067)$ e Colinas do Tocantins $(0,054)$. 
Os 131 municípios em estágio retardatário estão espalhados de norte a sul e de leste a oeste do Tocantins, conforme Figura 3. Todavia os municípios localizados na parte leste não estão interligados nos corredores de transportes, além do impedimento que separa o Rio Tocantins, como meio de locomoção para os municípios pobres, o custo de acessibilidade se torna elevado, e o deslocamento torna-se distante.

Pouco se alterou em 2010; continuaram os três municípios polos: Palmas $(0,60)$, indicador máximo, Araguaína $(0,231)$ e Gurupi $(0,137)$. Os municípios intermediários passaram a ser apenas três: Paraíso do Tocantins $(0,074)$, Porto Nacional $(0,065)$ e Miracema do Tocantins $(0,060)$. 0 total de municípios retardatários aumentou para 133, representando $96 \%$ do total dos municípios (Figura 3).

Analisando as variáveis econômicas entre 2000 e 2010, houve aumentos significativos; contudo ficaram concentradas em apenas três cidades: Palmas, Araguaína e Gurupi. Palmas, em 2010, elevou sua magnitude máxima desse indicador $(0,60)$, havendo uma concentração maior na capital. O PIB municipal de Palmas, em 2000, era cerca de R $\$ 660$ milhões de reais; em 2010, chegou a $R \$ 3,9$ bilhões de reais. Outra variável significativa foi o número de empregos formais, em 2000, Palmas tinha 51.817, passando em 2010 para 112.915 empregos formais, ou seja, mais que dobrou o número de empregos, um aumento de mais de $120 \%$ nesse período.

Figura 3 - Distribuição do Indicador Econômico no Território do Tocantins - 2000 e 2010

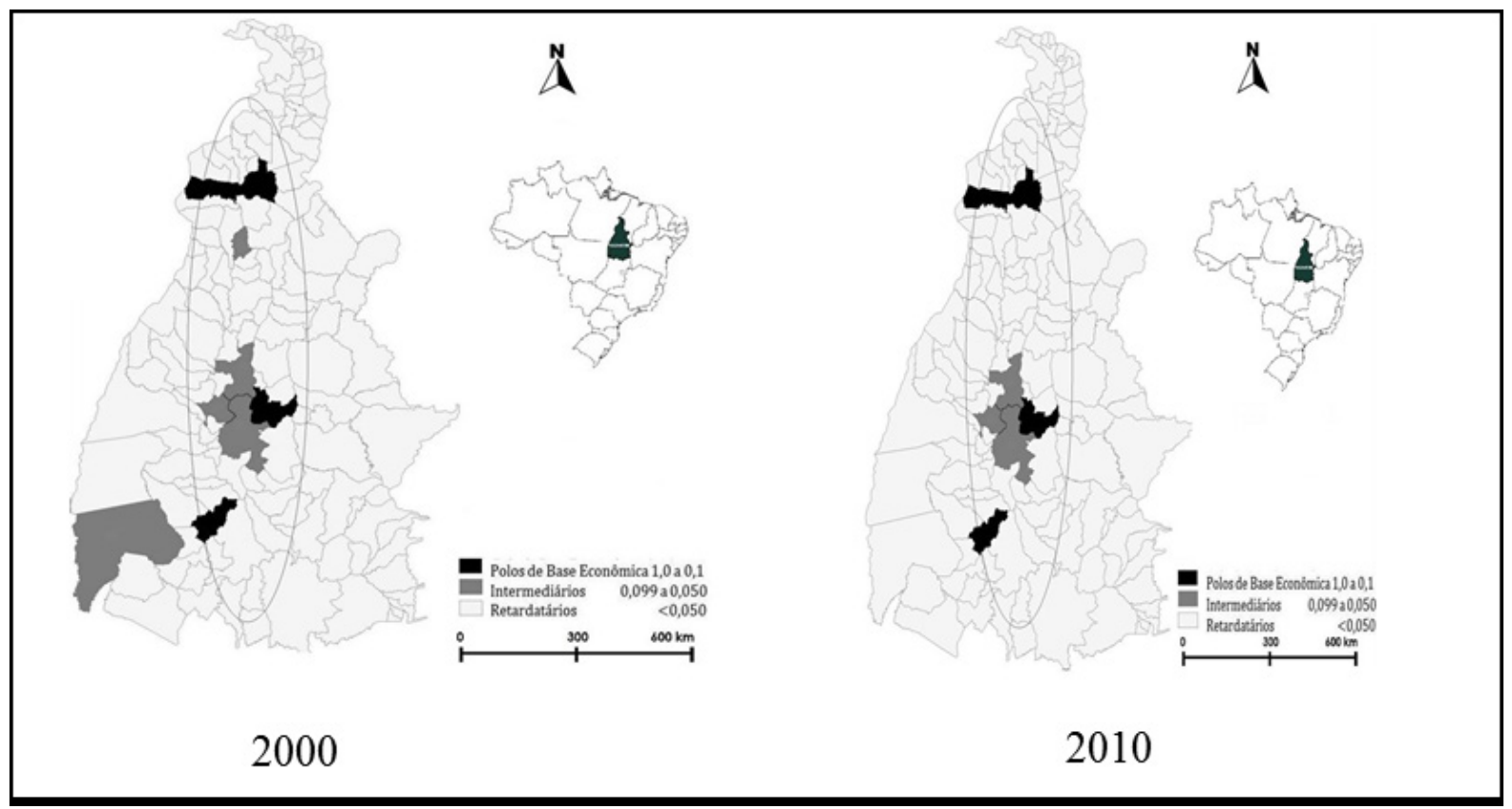

Fonte: Adaptado do IBGE (2000; 2010).

Analisando o emprego em 2010, constatou-se que 82 municípios contavam com o número de empregos formais entre 1 e 400, correspondendo a 60\% dos municípios. Havia, ainda, 35 municípios com capacidade de gerar empregos entre 401 a 990 empregos formais, em 2010, correspondendo a 25\%, e apenas 22 municípios com capacidade de gerar mais de mil empregos, correspondendo a 16\%. O município que gerou mais empregos em 2010 foi a capital, Palmas, com 112.915. Desse total, 68.115 foram gerados na administração pública; 20.071 no setor de serviços; 13.585 no comércio; e 6.084 na construção civil. O município que gerou menor número de emprego em 2010, foi Lavandeira, com apenas 13 empregos formais. 
Em 2010, a economia do Estado do Tocantins apresentou um dos melhores resultados em termos de crescimento do PIB, entre todos os estados do país. A participação relativa do PIB do total do estado, em 2010, das três principais cidades ficou assim distribuída: Palmas (18\%), Araguaína (11\%) e Gurupi (6\%), ou seja, essas três cidades somavam cerca de 35\% do total dos produtos agregados dos setores primários, secundários e terciários, produzidos no Tocantins em 2010, considerando que o Estado possui 139 municípios, e apenas essas três cidades concentram mais de $1 / 3$ do PIB do estado.

Quanto à geração de emprego formal, Araguaína, em 2010, contabilizava 25.005, Gurupi 15.104 e Palmas 112.915, dos 238.995 empregos gerados, ou seja, esses três municípios somavam 153.025, correspondendo a 64\% do total do emprego formal no Estado (MTE, 2010).

Segundo os dados da Sefaz-TO (2010), o imposto sobre circulação de mercadoria e serviços (ICMS) arrecadado nesses três municípios, considerados polos, também foi significativo. Araguaína arrecadou cerca de $\mathrm{R} \$ 26,75$ milhões de reais, Gurupi cerca de $\mathrm{R} \$ 18,56$ milhões, e Palmas arrecadou cerca de $\mathrm{R} \$ 50$ milhões de reais. O total de ICMS do estado em 2010 ficou próximo de $\mathrm{R} \$ 278,37$ milhões. Os três municípios juntos somaram $\mathrm{R} \$ 95,31$ milhões, correspondendo a $34 \%$, isto é mais de $1 / 3$ do total.

O ICMS é o imposto arrecadado sobre a circulação de mercadorias e serviços; como esses três municípios polarizam a economia do estado, há uma certa tendência de fuga de capital para esses lugares. A concentração dessa arrecadação nesses três municípios se deve ao fato de que, esses municípios têm maior capacidade de ofertar bens, serviços e lazer que, muitas vezes, não são encontrados nos municípios com base econômica retardatários.

A arrecadação do imposto sobre a propriedade de veículos automotores (IPVA) está ligada diretamente ao número de veículos automotores e a renda disponível para aquisição desses bens. Essas aquisições refletem como forma de bem-estar ou como forma de trabalho que o veículo representa. Araguaína, em 2010, arrecadou de IPVA cerca de R\$ 8,26 milhões, Gurupi, R\$ 3,16 milhões e Palmas $R \$ 13,12$ milhões de reais. A soma total nesses três municípios totalizou cerca de $R \$ 24,54$ milhões do total de R\$38,77 do Estado (SEFAZ-TO, 2010).

Isso representa 63\% do total de IPVA arrecadado, logo, infere-se, novamente, que esses três municípios concentram a maioria da frota de veículos, do Estado. É evidente que os municípios considerados retardatários, não possuem renda suficiente para aquisição desses bens, haja vista que, com um elevado índice de pobreza, com uma renda per capita de meio salário mínimo, dificilmente eles terão condições de manter um veículo; na realidade, muitos deles mal dão conta de manter sua própria sobrevivência.

Em relação aos municípios retardatários, a sobreposição se manteve entre 2000 e 2010, não havendo alterações nesse indicador, representados pelos 133 municípios em 2010, correspondendo 96\% do total, indicando uma fragilidade nas variáveis econômicas.

\subsection{O Indicador de Desenvolvimento Regional no território do Tocantins}

O Índice de Desenvolvimento Regional (IDR) foi construído a partir dos indicadores sociais e econômicos e representa o grau de desenvolvimento dos municípios tocantinenses. Uma vez estimado o IDR para cada município, foi possível ordená-lo segundo o grau de dinamicidade, dos 139 municípios do Estado do Tocantins, demonstrando que, no ano de 2000, havia 15 municípios classificados como polo de desenvolvimento (11\%), os 5 melhores foram: Palmas 
(0,871), Araguaína (0,507), Gurupi $(0,421)$, Paraíso do Tocantins $(0,242)$ e Porto Nacional $(0,223)$. O número de municípios classificados em estágio intermediário são 34, correspondendo a $24 \%$ do total dos municípios. Os melhores índices nessa faixa foram apresentados pelos municípios de Dianópolis (0,097), Figueirópolis (0,088), Palmeirópolis $(0,087)$, Arapoema $(0,082)$ e Miranorte $(0,080)$. Já os municípios retardatários em 2000 representaram 90, correspondendo a 65\% do total dos municípios; os cinco piores foram: Praia Norte $(-0,014)$, Barra do Ouro $(-0,015)$, Carrasco Bonito $(-0,017)$, Mateiros $(-0,021)$ e Esperantina $(-0,021)$.

Na região do Jalapão, não se verificou nenhum município polo, muito pelo contrário, nessa região está localizada grande parte dos municípios pobres, juntamente com a região do Bico do Papagaio. Esses municípios não conseguem se manter dentro do dinamismo da base de manutenção, ou seja, são caracterizados como retardatários, bem como estão fora da acessibilidade ao corredor de desenvolvimento, a BR-153, e nem estão ligados aos corredores menores estaduais com infraestrutura adequada. Em tais localidades não há postos de saúde, escolas e professores qualificados. Segundo os dados do PNUD (2000), esses municípios não conseguiram superar sua taxa de pobreza que, ainda, constitui um entrave no processo de desenvolvimento social e econômico.

O município Barra do Ouro possui $74 \%$ das pessoas pobres, Carrasco Bonito (85\%), Lagoa do Tocantins (80\%), Mateiros (72\%), Esperantina (81\%). Foram consideradas pessoas pobres as que sobrevivem com uma renda per capita de até meio (1/2) salário mínimo mensal. Essas taxas não são piores devido à transferência de renda via Bolsa Família, pensão, benefícios e aposentaria do meio rural do Governo Federal (PNUD, 2010).

A partir de 2010, verificou-se uma melhora sensível do IDR, os municípios polos passam a ser 16, os municípios intermediários passam de 34, em 2000, para 82, em 2010, correspondendo a 59\% do total do Estado. O grande avanço foi nos municípios classificados como retardatários, de 90, em 2000, para 41 municípios, em 2010, isto é, 49 municípios passaram a ser considerados intermediários. A participação percentual dos municípios considerados retardatários em 2000 era de 65\%, caindo para 29\% em 2010.

A Figura 4 representa a distribuição da localização dos IDR no território do Tocantins para os anos de 2000 e 2010. Observa-se que a concentração dos melhores IDR, assim como nas demais, estão concentrados no corredor da BR-153 (Belém-Brasília), onde acontece a dinâmica econômica. Os municípios polos acabam irradiando o processo de desenvolvimento para os municípios intermediários, estes, por sua vez, para os retardatários. 
Figura 4 - Distribuição da localização do IDR no Território do Tocantins - 2000 e 2010

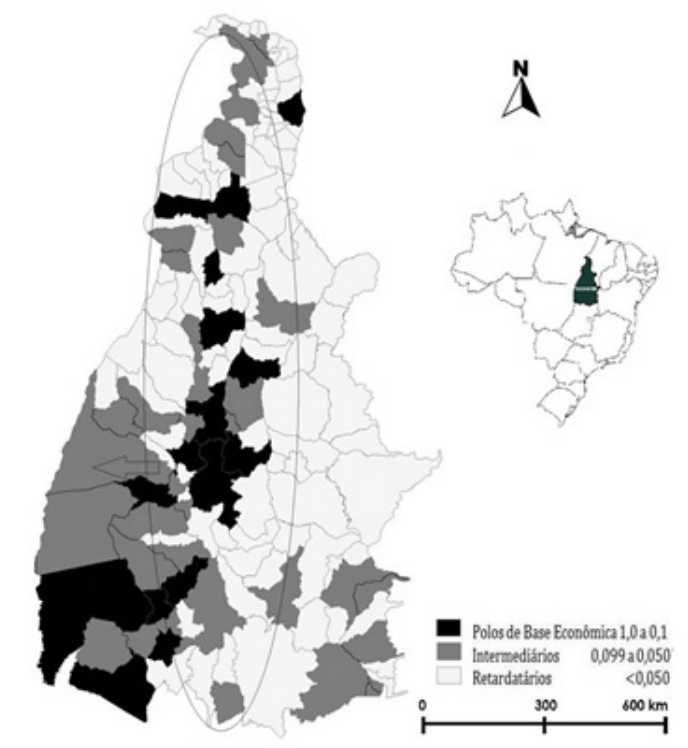

2000

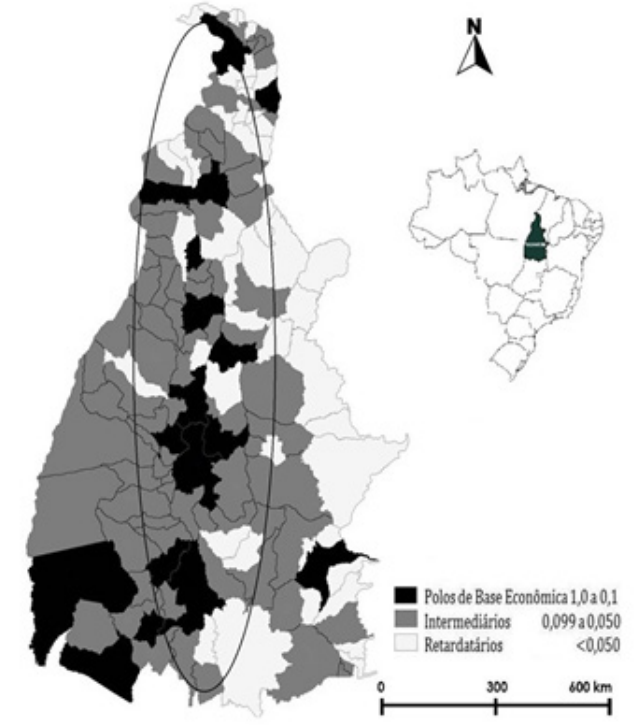

2010

Fonte: Adaptado do IBGE (2000; 2010).

Nessa dinâmica do processo de desenvolvimento regional, o estado do Tocantins tem se destacado na produção de soja para o mercado regional, nacional e global. Segundo dados apresentados pela Conab (2014), a região de interface entre os estados do Maranhão, Tocantins, Piauí e Bahia (MATOPIBA) produziu cerca de 3,5 milhões de toneladas de grãos, sendo a soja com 2,2 milhões de toneladas produzidas na safra de 2013/2014. Os principais municípios produtores de soja no Tocantins são: Campos Lindos, Guaraí, Palmas, Aparecida do Rio Negro, Brejinho de Nazaré, Tupirama, Tupirantins, Porto Nacional, Pedro Afonso, Figueirópolis e Cariri do Tocantins.

No setor de indústria de transformação, segundo informações da Secretaria de Planejamento do Estado do Tocantins (SEPLAN-TO, 2012), os principais municípios a serem contemplados com investimentos das indústrias de transformação são Campos Lindos, no norte do estado, Formoso do Araguaia, no sul, e Porto Nacional, na região de Palmas, fundamentalmente no setor de alimentos. Palmas e Miracema do Tocantins devem ser contemplados com investimentos em serviços públicos, especialmente em infraestrutura, que devem, em um futuro próximo, servir de incentivo para a instalação de novas empresas.

A indústria extrativa é outro segmento que deve contar com uma expansão a partir dos investimentos em transporte (com a Ferrovia Norte-Sul), aproveitando a existência de grande número de jazidas minerais (FEDERAÇÃO DAS INDÚSTRIAS DO ESTADO DO TOCANTINS [FIETO], 2010).

Apesar dos prognósticos positivos, ainda existem grandes desafios a serem superados para que esse potencial produtivo seja totalmente utilizado. Dentre eles se destaca o transporte, a necessidade de melhorar a infraestrutura de armazenamento e escoamento de grãos, pois existem poucas unidades de armazéns no Estado; deve-se pensar, também, no processamento da soja, milho e arroz pelas indústrias de transformação, agregando maior valor adicionado ao produto. 


\section{CONSIDERAÇÃO FINAIS}

A pesquisa contribui com uma análise do desenvolvimento regional no território do Tocantins, a partir da elaboração de IDR com as variáveis sociais e econômicas. A construção do IDR considerou a análise específica dos indicadores parciais inerentes ao cálculo das 17 variáveis sociais e econômicas entre 2000 e 2010 para os 139 municípios do Estado do Tocantins. Nesta pesquisa, o indicador econômico teve maior peso $(0,6)$ pois o município com melhor situação econômica possui mais condições para investir em infraestrutura básica, sem contar com a capacidade de gerar empregos e, assim, melhorar seu indicador social $(0,4)$.

As variáveis sociais que tiveram melhor desempenho no IDR foram: aumento nos gastos na área da educação, saúde, números médio de estudos, abastecimento com água encanada, esgoto e redução da taxa de pessoas pobres no Tocantins.

Analisando as variáveis econômicas entre 2000 e 2010, houve aumento significativo no PIB dos municípios, no emprego formal, na arrecadação do ICMS e IPVA. O conjunto de relações entre as variáveis sociais e econômicas influenciou no resultado final do IDR, a melhora no desempenho desses indicadores representou um avanço na qualidade de vida da população, bem como para o capital humano do estado.

De forma geral, a análise dos indicadores parciais sociais e econômicos permitiu a classificação dos municípios do território do Tocantins, em 2000, dos 139 municípios, apenas 15 (11\%) foram classificados como polos de desenvolvimento, e, em 2010, passou para 16 (12\%); os principais municípios polos do Tocantins são: Palmas, a capital do estado, Araguaína, Gurupi, Porto Nacional e Paraíso do Tocantins. Os municípios em estágio intermediário estavam assim distribuídos, em 2000, 35 municípios correspondendo a 24\% o que, em 2010, aumentou para 82 municípios (54\%). Já os municípios em estágio retardatário em 2000 eram 90, correspondendo a 65\%, em 2010 esse número ficou reduzido para 41 municípios, sendo que estes não conseguiram alterar seu IDR ao longo dos anos analisados, foi o caso de Mateiros, Lizarda, Esperantina, Barra do Ouro entres outros.

Assim os municípios classificados como polo de desenvolvimento possuem uma estrutura econômica favorável à geração de investimentos nos demais setores, alavancando a melhora das condições sociais e econômicas.

No decorrer dos anos analisados, pode-se inferir que a produção e a reprodução do capital no tempo e no espaço, no território do Tocantins, foram modificadas e transformadas pelas redes políticas e econômicas que aqui se instalaram: rodovias federais e estaduais, Ferrovia Norte-Sul, a Hidrovia Araguaia-Tocantins, comércio, serviços, indústrias tradicionais, aeroportos, agroindústrias e redes bancárias. A construção da BR-153, proporcionou os elos com os municípios do seu corredor e com os corredores menores, destacando os municípios que estão instalados ao longo dessa rodovia. Isso implicou a expansão, a ocupação de novas fronteiras agrícolas e a ampliação do capital.

Diante disso, foi possível demostrar quais são as possíveis limitações e potencialidades para o desenvolvimento regional no território do Tocantins, pois, a partir da base metodológica utilizada, foi possível apontar os locais que necessitam de políticas públicas, visando ao desenvolvimento social e econômico para que o Tocantins possa se desenvolver de forma sustentável. 


\section{REFERÊNCIAS}

BOISIER, S. Desarrollo (Local): ¿ de qué estamos hablando? In: BECKER, D. F.; BANDIERA, P. S. (Org.). Desenvolvimento local-regional: determinantes e desafios contemporâneos. Santa Cruz do Sul, RS: Edunisc, 2000. v. 1.

BOURDIEU, P. O poder simbólico. Lisboa: Difel; Rio de Janeiro: Bertrand Brasil, 1989.

BRESSER-PEREIRA, L. C. Crescimento e desenvolvimento econômico. BRESSERPEREIRA Website, 2008. Disponível em: http://www.bresserpereira.org.br/Papers/2007/07.22.CrescimentoDesenvolvimento. Junho19.2008.pdf. Acesso em: 10 mar. 2016.

COASE, R. H. The nature of the firm. Economic. New Series, v. 4, n. 16, p. 386-405, nov. 1937. Disponível em: https://onlinelibrary.wiley.com/doi/full/10.1111/j.1468-0335.1937.tb00002.x. Acesso em: 20 jan. 2016.

CONAB. Levantamentos de safras, 2013/2014. Disponível em: http://www.conab.gov.br/conteudos. php?a=1253\&t=/. Acesso em: 18 maio 2016.

FERRERA DE LIMA, J.; ALVES, L. R.; EBERHARDT, P. H. C.; BIANCO, T. S. Mensurar as desigualdades regionais no Brasil: proposta metodológica. In: ETGES, V. E.; AREND, S. C. (Org.). CEPAL: leituras sobre o desenvolvimento latino-americano. Santa Cruz do Sul, RS: Edunisc, 2012. p. 270-90.

FIETO. Incentivos Fiscais do Tocantins 2010. Palmas: FIETO, 2010. 40p. Disponível em: http://www.fieto. com.br/. Acesso em: 27 abr. 2016.

FURTADO, C. Desenvolvimento e subdesenvolvimento. Rio de Janeiro: Contraponto/Centro internacional Celso Furtado, 2009. 234p.

GUALDA, N. L. O Índice de Desenvolvimento Regional como fator de identificação de polos de crescimento regionais - uma tentativa de identificação para a economia paranaense. In: ENCONTRO DE ECONOMIA PARANAENSE, 2., 2003, Maringá, PR. Anais [...]. Maringá, PR: TAC - Multimídia, 2003. p. 566-83.

GUALDA, N. L. IDR - Proposta Metodológica. Texto para Discussão n. 15. Programa de Mestrado em Economia. Maringá, PR: Universidade Estadual de Maringá, 1995.

HAESBAERT, R. Territórios alternativos. 2. ed., 2. impressão. São Paulo: Contexto, 2009. 186p.

HAESBAERT, R. Des-territorialização e identidade: a rede "gaúcha" no Nordeste. Niterói, RJ: EDUFF, 1997.

IBGE. Contas Regionais do Brasil, 2014. Disponível em: http://www.ibge.gov.br/home/. Acesso em: 25 abr. 2016.

IBGE. Censos Demográficos, Econômicos e Agropecuários, 2000 e 2010. Biblioteca digital. Rio de Janeiro. Disponível em: www.ibge.gov.br. Acesso em: 20 fev. 2014

IPEADATA. Base de dados sociais e econômico entre 2000 e 2010. Disponível em: http://www.ipeadata. gov.br/. Acesso em: 20 mar. 2016.

LOPES, A. S. Desenvolvimento regional: problemática, teoria e modelos. 2. ed. Lisboa: Fundação Calouste Gulbenkian, 2001.

MTE. Relação Anual de Informações Sociais, 2000, 2010 e 2013. Disponível em: http://portal.mte.gov. br/rais/. Acesso em: 18 ago. 2016. 
NORTH, D. C. Custos de transação, instituições e desempenho econômico. São Paulo: Instituto Liberal, 1994.

NORTH, D. C. Institutions. Journal of Economic Perspectives, v. 5, n. 1, p. 97-112, 1991.

OLIVEIRA, C. Desigualdades regionais no Rio Grande do Sul: um enfoque da nova geografia econômica. Revista Redes, Santa Cruz do Sul, RS, v. 10, n. 2, p. 93-116, maio/ago. 2005. Disponível em: https://online. unisc.br/seer/index.php/redes/article/view/11070

PERROUX, F. O conceito de polos de crescimento. In: SCHWARTZMAN, S. (Org.). Economia regional: textos escolhidos. Belo Horizonte: CEDEPLAR, 1977.

PNUD. Relatório do Desenvolvimento Humano (RDH), 2000, 2010. Disponível em: http://hdrstats.undp. org/en/indicators/103106.html. Acesso em: 27 jan. 2015.

RAFFESTIN, C. Por uma geografia do poder. Tradução Maria Cecília França. São Paulo: Ática, 1993.

RODRIGUES, K. F.; FERRERA DE LIMA, J. Índice de desenvolvimento regional sustentável: uma análise das mesorregiões do Estado do Paraná no período de 2002 a 2008. Revista Geografar, Curitiba, PR, v. 8, n. 1, p. 175-202, jun. 2013.

SAQUET, M. A. Os tempos e os territórios da colonização italiana. Porto Alegre, RS: EST Edições, 2003.

SEFAZ-TO. Arrecadação de tributos municipais. Disponível em: http://sefaz.to.gov.br/. Acesso em: 4 maio 2016.

SEPLAN-TO. Informações Econômicas do Estado do Tocantins. Palmas, TO, 2012. Disponível em: http:// www.sefaz.to.gov.br/seplan/. Acesso em: 5 maio 2016.

SPOSITO, E. S. Contribuição à metodologia de ensino do pensamento geográfico. 2000. Presidente Prudente, SP: FCT/UNESP, 2000. (Tese de Livre Docência).

ZAOUAL, H. Nova economia das iniciativas locais: uma introdução do pensamento pós-global. Tradução Michel Thiollent. Rio de Janeiro: DP\&A/Consulado Geral da França/COPPE/UFRJ, 2006.

\section{Sobre os autores:}

Nilton Marques Oliveira: Doutor em Desenvolvimento Regional e Agronegócio pela Universidade Estadual do Oeste do Paraná (UNIOESTE), Toledo, PR. Mestre em Economia Aplicada pela Universidade Federal de Viçosa (UFV) e Graduado em Ciências Econômicas pela Universidade Estadual de Maringá (UEM). Professor do Programa de Pós-graduação em Desenvolvimento Regional e do curso de Ciências Econômica da Universidade Federal do Tocantins (UFT). Bolsista do Programa Institucional Produtividade em Pesquisa da UFT. Pesquisador dos Grupos de Estudos em Economia Aplicada e Interdisciplinar de Estudos e Pesquisa sobre Estado, Educação e Sociedade (Geipees) da Universidade Federal do Tocantins. Diretor de Avaliação da Pró-Reitoria de Avaliação e Planejamento (PROAP/UFT) de 2008 a 2012. Área de Pesquisa: Desenvolvimento Regional, com ênfase em economia regional e urbana, pobreza, desigualdades, análise regional e Economia do Tocantins. Possui diversos artigos e textos publicados em eventos e periódicos nacionais e internacionais. E-mail: niltonmarques@uft.edu.br 
Moacir Piffer: Economista, doutor em Desenvolvimento Regional, professor adjunto da UNIOESTE, Professor do Programa de Pós-Graduação em Desenvolvimento Regional e Agronegócio, membro do Grupo de Pesquisa em Agronegócio e Desenvolvimento Regional (GEPEC). Toledo, PR. E-mail: mopiffer@yahoo.com.br

Udo Strassburg: Doutor em Desenvolvimento Regional e Agronegócio na Unioeste, Toledo, PR. Professor do Curso de Ciências Contábeis da Unioeste, Cascavel, PR. Pesquisador do Grupo de Pesquisa em Contabilidade e Controladoria. Cascavel, PR. E-mail: udo.strassburg@unioeste.br 